\title{
RACIONALIDADE ADMINISTRATIVA NA EDUCAÇÃO À LUZ DA TEORIA DA AÇÃO COMUNICATIVAA
}

\author{
ADMINISTRATIVE RATIONALITY IN EDUCATION \\ IN THE LIGHT OF THE COMMUNICATIVE ACTION THEORY \\ LA RATIONALITÉ ADMINISTRATIVE DANS L'ÉDUCATION \\ À LA LUMIÈRE DE LA THÉORIE DE L'ACTION COMMUNICATIVE \\ RACIONALIDAD ADMINISTRATIVA EN LA EDUCACIÓN A LA LUZ \\ DE LA TEORÍA DE LA ACCIÓN COMUNICATIVA
}

Arilene Maria Soares de Medeiros*

\section{RESUMO}

O objetivo deste artigo consiste em apresentar, à luz da teoria da ação comunicativa, uma proposição critica de racionalidade administrativa para a educação, que possa consolidar-se em parâmetros democráticos e emancipatórios, como forma de reestruturação organizacional interna da escola. Esta proposiçāo enfrenta dificuldades que merecem ser devidamente analisadas, para não assumir uma dimensão simplesmente utópica, sem a menor repercussão prática no cotidiano da escola. As dificuldades politico-institucionais refletem a relação que se estabelece entre o Estado e a administração escolar. As dificuldades organizacionais dizem respeito ao funcionamento da escola por meio do Regimento Escolar, Conselho Escolar e Projeto Político-Pedagógico. Com esta análise, pretende-se demonstrar que a administração escolar reflete uma tensão entre as políticas e as práticas, entre o externo e o interno, possibilitando alteraçōes e inovações na escola.

Palavras-chave: Racionalidade administrativa. Regimento escolar. Conselho escolar. Projeto político-pedagógico. Administração escolar. Teoria da ação comunicativa.

\footnotetext{
* Doutora em Educação pela Universidade Federal de São Carlos (UFSCar, 2002). Professora da Faculdade de Educação da Universidade do Estado do Rio Grande do Norte (arilene.medeiros@bol.com.br).
} 


\section{INTRODUÇÃO}

Desde 1998, venho insistentemente discutindo a articulação entre a racionalidade administrativa da educação pública brasileira e a racionalidade comunicativa proposta por Habermas, como possibilidade de uma racionalidade diferente da instrumental, para o âmbito da administração educacional. O objetivo deste artigo consiste em apresentar uma proposição crítica de racionalidade administrativa que, à luz da teoria da ação comunicativa, possa consolidar-se em parâmetros democráticos e emancipatórios, primando pelas funçōes educativas da escola. Tal proposição apresenta inúmeras dificuldades, notadamente quando a racionalidade comunicativa encontra-se asfixiada pela racionalidade instrumental. Esta última - tão presente na administração educacional e, obviamente, não indiferente ao atendimento dos pressupostos do mundo sistêmico (Estado e mercado) - impede a construção de uma racionalidade administrativa democrática e emancipatória no contexto escolar.

As dificuldades refletem, em geral, as formas de como o Estado e o mercado têm acumulado forças políticas, sociais e institucionais que contrariam as proposiçōes críticas para o desenvolvimento de uma educação pública democrática e cidadã, pois em questão estão duas racionalidades que, embora diferentes e complementares no conjunto global da sociedade, demonstram interesses antagônicos entre si no interior das instituiçõos educativas. As forças sociais, políticas e institucionais - compatíveis à racionalidade instrumental - são forças exógenas à escola que, endogenamente, são assimiladas pelos profissionais da educação, incorporando-se, portanto, aos interesses e ações que dão sustentabilidade ao desenvolvimento dessa racionalidade no espaço escolar. Isto é o suficiente para expressar a atualidade histórica da tese habermasiana de que o mundo vivido encontrase colonizado pelas estruturas do mundo sistêmico, tanto "na forma de uma burocratização excessiva", quanto na forma "de um formalismo exacerbado" (PINTO, 1996, p. 103).

De modo geral, consoante à cultura de dominação e à história de exclusôes sociais, as escolas públicas brasileiras adquiriram um jeito de encaminhar suas atividades pedagógicas e administrativas que, de alguma forma, dificulta a legitimação de processos participativos e democráticos na escola. As dificuldades impostas para a construção de uma racionalidade democrática são inúmeras e, neste artigo, queremos nos ater às dificuldades político-institucionais e organizacionais, confirmando que elas representam configurações sociais de diferentes ordens, embora estabeleçam relações entre si na constituição administrativa da escola. 


\section{DA CRÍTICA À PROPOSIÇÃO CRÍTICA: UMA RACIONALIDADE ADMINISTRATIVA EM DEBATE}

Fundamentada na racionalidade comunicativa, a proposição de uma nova racionalidade para a administração da educação pública se configura como amplo espaço para o questionamento e o possível entendimento das pretensões de validez. Esta proposição se diferencia de perspectivas teóricas que defendem a racionalidade como adoção de métodos e técnicas provenientes, principalmente, da administração empresarial, que, ao assumir o caráter essencialmente instrumental-burocrático da ação administrativa, assegura a eficiência da educação afinada com os interesses da sociedade capitalista. Neste caso, racionalidade administrativa não se restringe à aplicação de técnicas e procedimentos, pelo fato de materializar-se pela via da argumentação e da contra-argumentação, tendo em perspectiva o entendimento recíproco em torno de questôes centrais relativas ao pedagógico, no contexto escolar.

Nos casos em que as pretensões de validez são problematizadas, ao invés da imposição de idéias advindas do diretor escolar, como se elas não fossem susceptíveis a crítica, instaura-se um processo argumentativo e contra-argumentativo, como possibilidade de viabilizar consensos provisórios que possam favorecer e atender a interesses coletivos. Nesse contexto, imbuída da idéia do consenso racionalmente motivado, a administração escolar passa a realçar os interesses coletivos da escola, na medida em que fortalece a disposição dos indivíduos a entenderem-se reciprocamente sobre eles. Percebe-se que a contribuição da racionalidade comunicativa para a constituição de uma nova racionalidade administrativa para a educação evidencia mudanças - tanto do ponto de vista teórico quanto prático -, podendo ser materializadas com a adoção de novas referências conceituais e a condução de novas formas de organização. Tudo isso reconhecendo que a função da administração dentro da escola é preservar os fins educativos e estabelecer formas e procedimentos para alcançá-los. O delineamento das mudanças de uma racionalidade para outra fica explicitado a partir daquilo que a escola consegue mobilizar em termos teóricos e práticos, conforme o quadro a seguir: 
Quadro I: Administração Educacional entre as racionalidades instrumental-burocrática e comunicacional-democrática

\begin{tabular}{|c|c|c|}
\hline & $\begin{array}{l}\text { RACIONALIDADE } \\
\text { INSTRUMENTAL- } \\
\text { BUROCRÁTICA }\end{array}$ & $\begin{array}{l}\text { RACIONALIDADE } \\
\text { COMUNICACIONAL- } \\
\text { DEMOCRÁTICA }\end{array}$ \\
\hline \multirow[t]{8}{*}{$\begin{array}{l}\text { Referências } \\
\text { conceptuais }\end{array}$} & $\begin{array}{l}\text { Campo de aplica o das teorias de } \\
\text { administra o empresarial }\end{array}$ & $\begin{array}{l}\text { Campo de aplica o das teorias } \\
\text { pedag gicas }\end{array}$ \\
\hline & Universalidade & Especificidade \\
\hline & $\begin{array}{l}\text { Valoriza o dos condicionamentos } \\
\text { macroestruturais }\end{array}$ & $\begin{array}{l}\text { Valoriza o dos condicionamentos macro e } \\
\text { microestruturais }\end{array}$ \\
\hline & $\begin{array}{l}\text { Processo de comunica o fundamentado } \\
\text { na informa o }\end{array}$ & $\begin{array}{l}\text { Processo de comunica o fundamentado } \\
\text { na argumenta o e contra-argumenta o }\end{array}$ \\
\hline & Consenso como nega o dos conflitos & $\begin{array}{l}\text { Consenso como possibilidade de unidade } \\
\text { na multiplicidade }\end{array}$ \\
\hline & Centraliza o & Descentraliza o \\
\hline & Bipolariza o entre meios e fins & Media o entre meios e fins \\
\hline & Condi o pol tica acoplada & Condi o pol tica inerente \\
\hline \multirow{5}{*}{$\begin{array}{l}\text { Formas de } \\
\text { organização }\end{array}$} & Manuten o de regras e normas oficiais & Cria o de regras e normas internas \\
\hline & $\begin{array}{l}\text { Hierarquiza o de fun es como exerc cio } \\
\text { de poder }\end{array}$ & $\begin{array}{l}\text { Respeito s especificidades das fun es com } \\
\text { a democratiza o do poder }\end{array}$ \\
\hline & Verticaliza o das decis es & Horizontaliza o das decis es \\
\hline & Formalidade excessiva & Formalidade necess ria \\
\hline & Imposi & Negocia o \\
\hline
\end{tabular}

Fonte: Organizado pela autora.

No âmbito da administração educacional, fala-se da necessidade de a administração articular-se com o pedagógico na escola; entretanto, isso é negado pelos paradigmas de administração empresarial e negligenciado por paradigmas que, de forma sub-reptícia, instrumentalizam a ação e a concepção de administração escolar. $O$ engessamento da prática do diretor escolar é conseqüência de uma racionalidade esquivada de suas potencialidades democráticas e emancipatórias, portanto, compatível ao modelo de racionalidade instrumental imperativa nas sociedades atuais. A racionalidade administrativa - a qual está sendo proposta - é ampla em sua constituição teórica, porque não tem a menor pretensão de desmerecer as diferentes abordagens (macro e microestruturais) que dão sustentação teórica e prática a uma administração escolar desvinculada dos pressupostos da administração empresarial; é democrática, porque parte do pressuposto de que todos, indistintamente, têm as mesmas condições de participação no processo de decisão que explicita os fins (a política pedagógica) da escola e os meios utilizados para atingi-lo; é processual, porque as decisóes em torno da ação escolar estão respaldadas pela coletividade e susceptíveis à crítica, cabendo ao diretor escolar estabelecer sua reorientação constante, em termos de objetivos e prioridades. 
Assim, é evidente que a opção dos gestores, no caso dos processos de tomada de decisão em um modelo alternativo de gestão, deve se situar fundamentalmente no campo democrático. A aceitação de que tomar decisōes é um processo e, mais do que isso, um processo coletivo e não pessoal ou subjetivo, garantido por uma prerrogativa de quem, por imperativo burocrático, ocupa cargos nas organizaçōes, é fundamental para se construir um modelo de gestão fundado na racionalidade cultural e comunicativa (GENTILINI, 2001, p. 49).

Reconhecidamente, no contexto dos modelos de administração conservadora, o processo de tomada de decisão constitui um processo centralizador, no qual o dirigente da organização toma as decisōes e comunica-as, para que os dirigidos possam atuar em conformidade a elas. A aceitação das decisões, de forma inconteste, por parte dos dirigidos, funciona como uma espécie de obediência ao (co)mando, pois, em todos os espaços e momentos da organização, a imposição se sobrepõe à democratização. A comunicação é apenas a formalização de informações. Nessa perspectiva de compreensão, Simon (1971) se destaca à medida que sua construção teórica apresenta indicadores de como o comportamento humano encontra-se moldado às decisões tomadas no ápice da hierarquia da organização; os indivíduos são induzidos à passividade, à aceitabilidade de sua condição subserviente. O processo de tomada de decisão consiste em mero mecanismo de determinação do poder de quem, no plano administrativo, dispõe das condições técnicas para tomar decisões que visam afetar e/ou alterar os comportamentos dos indivíduos.

Quando se defende a racionalidade administrativa como tomada de decisão coletiva e, em última instância, consensual, o significado ritualístico e tradicional da comunicação entre os indivíduos - que decidem e que executam o decidido - não encontra consistência, pois a racionalidade comunicativa é a possibilidade de os indivíduos assumirem dialeticamente sua condição de falante e ouvinte, nos variados espaços e tempos em torno de pretensões comuns.

Dito isto, ressalta-se ainda a administração escolar como atividade-meio, que é uma tendência epistemológica hegemônica na área. Contudo, percebe-se claramente que tal tendência tem sido insuficiente para a concretização de uma racionalidade administrativa democrática e emancipatória, construída nos fluxos da comunicação em que os indivíduos colocam o que pensam, decidem, expressam suas dúvidas e questionamentos, argumentam suas pretensões de validez. A administração escolar como atividade-meio e o ensino como atividade-fim engendram, segundo Saes e Alves (2003), conflitos funcionais nas instituições escolares, restando aos diretores a responsabilidade de executar as atividadesmeio e aos professores a realização das atividades-fim. Tais conflitos, embora assumam suas particularidades no contexto institucional das escolas, "devem ser vistos, no plano mais geral, como um espelho das estruturas da sociedade capitalista" (p. 19). Com a existência desses conflitos, cristaliza-se uma concepção de escola bipolarizada entre meios e fins, entre os profissionais (diretores e professores), mas que, em virtude da sobreposição dos meios em relação aos fins, a escola fortalece, por um lado, a racionalidade instrumental-burocrática e distancia-se, por outro, de suas funções educativas, que consistem na formação da personalidade, na divulgação da cultura e na socialização das regras sociais, cuja racionalidade subjacente é a comunicativa.

Admite-se que a racionalidade administrativa, com base na teoria da ação comunicativa, é uma proposição crítica para que a administração escolar transcenda sua perspectiva 
reducionista de percebê-la tão-somente como meio, instrumento; ela é, ao mesmo tempo, fim e meio. Fim que não nega nem se confunde com a especificidade do trabalho do professor que, na sala de aula, é ensinar algo aos alunos. Trata-se de um fim pedagógico inerente às relaçōes intersubjetivas, nas quais os indivíduos (diretores, professores, funcionários, alunos e pais), em suas condições de falante e ouvinte, levantam questionamentos, encaminham decisões e aprendem reciprocamente em decorrência disso. Meio que não se encerra em si mesmo e, por isso, não se desvincula da racionalidade democrática e emancipatória. De pouco adiantaria a disposição de uma racionalidade construída intersubjetivamente, entendida como processo de tomada de decisão consensual e coletiva acerca do pedagógico, se não houvesse a capacidade criativa de utilização racional de recursos (financeiros, materiais, administrativos e pedagógicos) para a implementação de tais decisões. O que pode fazer um diretor escolar sem a utilização racional de recursos para atender a decisōes tomadas?

É essa dimensão pedagógica da administração escolar, escamoteada pelas abordagens empresariais, que nos possibilita fazer a seguinte ilação: a administração é uma ação essencialmente política. Tudo isso significa uma proposição crítica e prospectiva de administração que, não desconsiderando sua especificidade no interior das práticas escolares, assume o imenso desafio de enfrentar as posições dicotômicas que marcaram tradicionalmente o pensamento moderno.

Essa nova concepção de administração contribui para se repensar e (até mesmo) superar o reducionismo, que fez da administração um espaço institucional necessário à instalação da burocracia, do controle do trabalho de outrem, do exercício da dominação, negando-lhe substancialmente sua dimensão pedagógica, portanto, política. Comumente, a dimensão política da administração lhe é amputada na medida em que se convencionou entendê-la como antecedência do processo administrativo, uma vez que os fins precedem os meios (PARO, 1993).

A administração - enquanto processo argumentativo e contra- argumentativo em torno das questôes pedagógicas - tem uma dimensão política inerente, quer seja no momento das decisōes a serem tomadas, quer seja nos encaminhamentos para a implementação delas. De uma forma ou de outra, a administração estará assumindo sua dimensão política, porque lhe cabe a coordenação comunicativa das ações dos indivíduos que participam da vida cotidiana escolar.

A articulação entre o político e o administrativo não pode ser vista como um acoplamento $a$ posteriori entre duas dinâmicas originariamente distintas. A questão política se coloca a partir da diversidade de indivíduos e grupos, de cujas interaçôes resultam decisões que são tomadas. A questão administrativa, por sua vez, resulta da necessidade de coordenar tais interaçôes. Por isso a administração da educação tem um caráter inerentemente político, e a dimensão política da educação necessita ser administrada (BOUFLEUER, 1997, p. 92).

Nessa linha de raciocínio, é fundamental que o diretor escolar reconheça e exercite sua função de articulador das decisões, associada à implementação das mesmas. Os processos argumentativos de decisão e de ação colocam os indivíduos frente à própria condição pedagógica (política) da administração, em que os sujeitos pensam e refletem 
sobre si e sobre os outros, decidem, questionam e aprendem. O diretor não se comporta como um controlador do trabalho alheio, mas como um falante-ouvinte como qualquer outro, que participa dos processos argumentativos e, conseqüentemente, da implementação das decisões acordadas coletivamente.

\section{DA PROPOSIÇÃO CRÍTICA ÀS DIFICULDADES: UMA RACIONALIDADE ADMINISTRATIVA POSSIIVEL}

Uma racionalidade administrativa que ponha em prática os pressupostos da racionalidade comunicativa - a crítica permanente, a argumentação e a contra-argumentação, o consenso racionalmente motivado - enfrenta dificuldades que precisam ser devidamente analisadas, para que tal proposição não assuma uma dimensão simplesmente utópica, sem a menor repercussão prática que possa auxiliar na condução dos sérios problemas e desafios com que os diretores escolares lidam cotidianamente. Deve-se, por outro lado, ressaltar que a racionalidade administrativa democrática não tem poder para resolver todos os problemas enfrentados pela escola pública - porque não se constitui como fantasmagoria - mas possui certamente pressupostos que possibilitam, efetivamente, sua democratização. Se isto não é o suficiente, é o fundamental para se avançar nas formas organizacionais da escola.

Entende-se que as dificuldades são encadeamentos de um processo mais amplo e complexo da própria sociedade. Diante disso, cabe reafirmar que um dos pressupostos básicos para as análises acerca da escola refere-se exatamente à própria sociedade, erigida por um tipo de racionalidade instrumental, em torno da qual os indivíduos se mobilizam para assegurar seu espaço na teia de relações sociais, cujos interesses representam o fortalecimento da dominação, do poder, da desagregação e da desigualdade social. Tal pressuposto é central nas análises dos teóricos frankfurtianos: Adorno, Horkheimer, Marcuse e Habermas. Porém, podemos dizer que, com exceção de Habermas, todos os demais acabaram não enxergando alternativas possíveis para a desinstrumentalização da subjetividade humana - por via da racionalidade - em virtude da apoteose da racionalidade instrumental nos contextos das sociedades atuais.

Para o desenvolvimento de um estudo da racionalidade administrativa democrática na escola não se deve abrir mão desse pressuposto macroestrutural que é o desempenho da racionalidade instrumental nos variados espaços e esferas da vida humana, a fim de não correr o risco de realização de análises apressadas e descontextualizadas, culpando, de um lado, a própria escola pelos péssimos resultados que a mesma produz e, de outro, não percebendo que ela, mesmo sendo reflexo de um tipo de racionalidade que se empreende na sociedade, pode ser contraproducente à lógica sistêmica e, desta feita, contribuir efetivamente para a construção de uma racionalidade administrativa democrática.

As dificuldades político-institucionais são bastante conhecidas e difundidas no campo da administração educacional. Dizem respeito concretamente à relação entre o Estado e a administração escolar; a burocratização entra na tessitura política como mecanismo primordial que o Estado dispóe para obstaculizar as relações democráticas entre os indivíduos na escola. Para Weber (2000), o desenvolvimento do aparelho burocrático numa 
determinada sociedade é conseqüência da complexificação do próprio Estado, cuja irradiação atinge as demais organizaçóes sociais. De acordo com o pensamento weberiano, a burocracia representa:

a forma mais racional de exercício de dominação, porque nela se alcança tecnicamente o máximo de rendimento em virtude da precisão, continuidade, disciplina, rigor e confiabilidade - isto é, calculabilidade tanto para o senhor quanto para os demais interessados -, intensidade e extensibilidade dos serviços, e aplicabilidade formalmente universal a todas as espécies de tarefas (WEBER, 2000, p. 145).

A burocracia acaba se justificando no tecido social, por ser um meio que exerce uma determinada superioridade, em detrimento de outros meios, em virtude de seu caráter puramente técnico. Ademais, ela se transforma em sinônimo de administração eficiente e racional, haja vista sua capacidade de proporcionar uma dominação que, via legalidade, é incorporada pelas organizaçôes, ou seja, pelos indivíduos, como sendo uma dominação "justa" e "correta". É de se notar o quanto a administração educacional assumiu essa projeção da burocracia, pois, tanto do ponto de vista teórico quanto prático, fez incorporações nesse sentido ao longo de sua história. O diretor escolar está no cargo para desempenhar suas competências legais, o que requer determinação, precisão e muita disciplina para acompanhar e controlar, com bastante avidez, o trabalho alheio. Toda essa responsabilidade requerida ao diretor escolar é acrescida mediante a nomeação arbitrária realizada por alguns Sistemas Públicos de Ensino - a exemplo do Estado do Rio Grande do Norte. À revelia da Constituição de 1998 e da Lei de Diretrizes e Bases da Educação Nacional (LDB) 9.394/1996, continuam a negar o princípio de gestão democrática, quando adotam a forma de nomeação mediante a escolha compatível com a trama da política partidária.

Além da burocratização - substrato de um modelo administrativo racional e eficiente -, assiste-se a uma crise de legitimação do sistema administrativo público, que se soma na lista dos obstáculos político-institucionais, quando a matéria é a racionalidade administrativa democrática para as escolas públicas. A crise de legitimação reflete as profundas contradições entre a regulamentação da política (aqui educacional) e a efetivação de seus preceitos. Tal crise consiste numa crise de governabilidade. Basta vermos que a gestão democrática se transformou em discurso comum - difundido e incorporado por progressistas e (neo)conservadores. Entretanto, requer-se a devida sensatez para não confundirmos aparência e essência.

No fundo, com a política educacional neoliberal, a gestão democrática passou a assumir a conotação de transferência de responsabilidade dos sistemas de ensino para as instituições escolares, demonstrando que a autonomia absorve uma conotação mais financeira do que pedagógica; a descentralização é mais de recursos e de tarefas (desconcentração) do que política (tomada de decisão pelos indivíduos atuantes na escola); a participação mais consultiva do que deliberativa. Não se tem uma racionalidade administrativa democrática quando a autonomia é apenas financeira, quando a descentralização é de recursos e de tarefas ou quando a participação é apenas regimental. Lima (2002, p. 1) afirma que "não existe gestão democrática na escola, mas tentativas instrumentalizadoras que visam sua democratização". Sua justificativa é a de que a ausência de 
uma sociedade democrática acaba por impossibilitar a implementação de uma gestão democrática. Pondera-se também que a racionalidade administrativa democrática, articulada ao referencial habermasiano, constitui uma tentativa mais profunda de gestão democrática, pois não é democratizando o processo de escolha de diretores via eleição, nem criando os órgãos colegiados, que se garante efetivamente uma nova racionalidade na escola. Aliás, percebe-se que, mediante a existência dos órgãos colegiados e dos demais aparatos democráticos que a escola disponibiliza atualmente, há necessidade de qualificar sua democracia interna sem ter que ficar na estreita dependência, esperando que a mudança na sociedade aconteça para que a escola possa sinalizar crescimento democrático.

As dificuldades organizacionais referem-se ao funcionamento e à organização propriamente dita das escolas. Grosso modo, a forma como a escola se organiza e funciona, por dentro, pouco contribui para uma racionalidade administrativa democrática e emancipatória, por causa de sua vinculação direta com a racionalidade instrumental-burocrática. Ademais, mesmo diante de tal constatação, é preciso assinalar que a escola, pelo que dispõe em termos de recursos organizacionais, não apenas reproduz as prescrições que a política educacional determina, mas também pode produzir inovaçóes internas a partir de como seus recursos organizacionais funcionam. Assim, acredita-se que os recursos organizacionais internos, quando vinculados à racionalidade comunicacional-democrática, podem favorecer uma nova organização escolar, conforme quadro demonstrativo a seguir:

Quadro II: Funcionamento de recursos organizacionais da escola sob a ótica das racionalidades instrumental-burocrática e comunicacional-democrática

\begin{tabular}{|c|c|c|}
\hline $\begin{array}{l}\text { RECURSOS } \\
\text { ORGANIZACIONAIS } \\
\text { DA ESCOLA }\end{array}$ & $\begin{array}{l}\text { RACIONALIDADE } \\
\text { INSTRUMENTAL- } \\
\text { BUROCRÁTICA }\end{array}$ & $\begin{array}{l}\text { RACIONALIDADE } \\
\text { COMUNICACIONAL- } \\
\text { DEMOCRÁTICA }\end{array}$ \\
\hline \multirow[t]{3}{*}{ Regimento Escolar } & $\begin{array}{l}\text { Reprodu o das normas e regras } \\
\text { oficiais }\end{array}$ & $\begin{array}{l}\text { Produ o de normas e regras } \\
\text { internas }\end{array}$ \\
\hline & nfase na estrutura formal & $\begin{array}{l}\text { nfase nas estruturas } \mathrm{n} \text { o-formais e } \\
\text { informais, sem desconsiderar as } \\
\text { formais }\end{array}$ \\
\hline & Conformismo & Inconformismo \\
\hline \multirow[t]{4}{*}{ Conseho Escolar } & Consultivo & Consultivo e deliberativo \\
\hline & Autonomia decretada & Autonomia constru da \\
\hline & A o estrat gica & A o comunicativa \\
\hline & Regime de vota o & Possibilidade de consenso \\
\hline \multirow[t]{3}{*}{ Projeto Político-Pedagógico } & $\begin{array}{l}\text { Participa o dos indiv duos em } \\
\mathrm{n} \text { veis elementares —estudos } \\
\text { preliminares }\end{array}$ & $\begin{array}{l}\text { Participa o dos indiv duos em } \\
\mathrm{n} \text { veis elementares e complexos } \\
\text { - sistematiza o/implementa o }\end{array}$ \\
\hline & Preocupa o com o produto & $\begin{array}{l}\text { Preocupa o com os indiv duos e } \\
\text { com o processo }\end{array}$ \\
\hline & Condi o institu da & Condi o institu da e instituinte \\
\hline
\end{tabular}

Fonte: Organizado pela autora. 
O Regimento Escolar - pensado à luz da racionalidade comunicativa - representa uma das possibilidades concretas de a escola instaurar regras e normas que impulsionem o desenvolvimento de sua democracia interna, enfrentando os procedimentos, os princípios e pressupostos de uma administração escolar, acionada para atender à racionalidade instrumental-burocrática. A democracia não significa a ausência de regras e normas, até porque a convivência entre os indivíduos pressupõe a existência delas. Todavia, uma organização escolar democrática exige o rompimento da perspectiva que concebe o Regimento Escolar apenas como reprodução da estrutura formal da organização, que gera conformismo, dispersão e obediência, tornando-se uma camisa de força dentro da escola, que inibe a participação dos indivíduos e favorece a cristalização do poder da administração escolar. Para que tal rompimento venha realmente a acontecer, o Regimento Escolar deve estar atualizado e fundamentado em pressupostos que possam garantir sua própria reestruturação e, conseqüentemente, provocar a reestruturação organizacional da escola.

O Regimento Escolar tem a responsabilidade de traçar as regras gerais da escola, para que a mesma possa garantir espaços de convivência humana. Mesmo com a existência do Regimento Escolar, as ações, os comportamentos e as relações entre os indivíduos não são completamente previsíveis na escola, o que possibilita alteraçôes e inovações organizacionais. As análises de Lima (2001) revelam que a escola, como organização, tem um "funcionamento díptico", à proporção que não se configura totalmente burocrática nem democrática, entretanto, expressa simultaneamente as duas faces, podendo uma tendência sobrepor-se a outra a depender das circunstâncias, dos indivíduos envolvidos, das orientações dadas, das decisões tomadas. A escola não constitui uma organização homogênea na forma e no conteúdo, como muitos pretendem, por isso seu Regimento não representa o conjunto das açôes, comportamentos e relaçoos que os indivíduos estabelecem entre si.

São muitos os colegiados de que a escola dispõe, no entanto, o interesse é tecer comentários em torno do Conselho Escolar, por ser considerado um dos mais significativos na reestruturação organizacional da escola, porque, quando funciona democraticamente, tem a capacidade política de promover consensos racionalmente motivados, capazes de estimular e fortalecer práticas coletivas no interior da escola. Pinto (1996) reconhece que o Conselho Escolar, da forma como vem se configurando no âmbito das instituições educativas, acaba reforçando a racionalidade instrumental-burocrática, principalmente quando se percebe que ele exerce a função básica de "homologar decisōes (calendários, coordenadores, reposição, recuperação) reguladas por resoluçōes da Secretaria da Educação" (PINTO, 1996, p. 127), transformando-se em um Conselho Escolar, sem autonomia para deliberar decisóes internas que respeitem as expectativas e as necessidades dos indivíduos envolvidos com a escola.

A política educacional defende a criação de colegiados para que os sistemas públicos de ensino projetem graus progressivos de autonomia pedagógica, financeira e administrativa para a escola, conforme regulamentação do Artigo 15 da LDB 9.394/1996. Porém, o que se evidencia é a voz silenciada da escola, porque negada mediante as cobranças da racionalidade instrumental-burocrática, restringindo a atuação do Conselho Escolar à iniciativa de validar decisões externas. Nessa linha de argumentação, o Conselho Escolar enfrenta também uma espécie de colonização do mundo sistêmico. 
Constata-se o funcionamento arbitrário das práticas administrativas, inclusive daquelas supostamente democráticas e participativas, predominando as formas de um agir estratégico, as quais favorecem o desenvolvimento de uma lógica organizacional escolar que obstaculiza as iniciativas da racionalidade comunicacional-democrática. Não é de todo suficiente para a democracia a existência de instâncias colegiadas, conforme se percebe com o Conselho Escolar, porque a democracia interna na escola presume, além da existência de canais formais de organização democrática, canais de comunicação e de relação interpessoais calcados na crítica constante, no respeito ao outro, no entendimento recíproco. Está deflagrado que a democracia na escola não é assegurada pela existência dos colegiados, mas pela forma como estes atuam cotidianamente. Ademais, no contexto da racionalidade comunicacional-democrática, o Conselho Escolar tem o papel fundamental de exercitar processos coletivos e consensuais de tomada de decisões, inclusive proporcionando formas de democratização que avancem em relação àquelas propaladas pela racionalidade instrumental-burocrática. Enfim, o Conselho Escolar contribui para a instauração de uma nova organização interna na escola, quando assume sua condição de mecanismo legitimador da democracia, da autonomia e da participação, não por decreto, mas por conquista e construção coletiva cotidiana.

O Projeto Político-Pedagógico é outro recurso organizacional que se evidencia no sentido de que a escola possa utilizá-lo em prol das mudanças no seu interior. É evidente o quanto a escola tem dispensado a esse recurso uma atenção meramente formal, com a finalidade de prestação de contas junto aos órgãos superiores, inclusive atropelando a participação dos indivíduos nos processos mais complexos, como sua sistematização e implementação. Tudo isso é dificultado pela falta de uma característica básica que deve permear qualquer produção de construção coletiva, em todos seus momentos: o estabelecimento de consensos racionalmente motivados, até para que os indivíduos envolvidos possam sentir-se representados.

A discussão, a sistematização e a implementação de um Projeto Político-Pedagógico são competência da escola, portanto, cabe a ela perscrutar as possibilidades de alterações organizacionais. Um Projeto Político-Pedagógico não deve preocupar-se tão-somente com o produto que aparece materializado em forma de documento, para não perder sua capacidade de intervenção e de mudança. A formatação do Projeto Político-Pedagógico como um documento é uma prioridade escolar, mas não é uma exclusividade. Quando a preocupação se volta exclusivamente para o produto, o instituído se enaltece e o instituinte se arrefece, porque o Projeto Político-Pedagógico acaba assumindo uma feição burocratizante.

No âmbito da ação comunicativa, o Projeto Político-Pedagógico significa mais do que documentação, pois não é simplesmente o produto que lhe interessa, mas o processo interativo que provoca acordos e redireciona práticas coletivas. Enfim, o Projeto PolíticoPedagógico tem uma dimensão instituída que não pode ser negada, nem negar a dimensão instituinte, sob o risco de descaracterizar-se como capacidade de criação e de inovação organizacional. 


\section{À GUISA DE CONCLUSÃO}

A racionalidade administrativa democrática e emancipatória, ao se apresentar como uma possibilidade, enfrenta dificuldades políticas, institucionais e organizacionais. $\mathrm{O}$ conjunto das dificuldades mostra a necessidade do devido cuidado, para não atomizar a escola, nem considerá-la apenas como propiciadora da reprodução e da uniformização centralizadora. Esse é o exercício teórico que deve ser feito, pois a realidade educacional atual não nos permite deflagrar compreensões reducionistas. Isso parece bastante oportuno para a área da administração educacional, que, por um longo período, foi vista e compreendida apenas como resultante da macroestrutura política e social. A administração escolar consiste numa tensão entre as políticas e as práticas escolares; entre o externo e o interno.

A racionalidade administrativa democrática é a manifestação da autonomia da escola, em termos pedagógicos, administrativos e financeiros, cujo desdobramento estaria respaldando o fortalecimento da escola como uma organização que preza pela liberdade dos indivíduos, pela democracia nas relações, pela participação dos sujeitos nos processos de decisão. Levando a cabo tal argumentação, qualquer ação (interna ou externa) que venha a interferir negativamente nessas prerrogativas de uma administração democrática trará dificuldades para a concretização de uma racionalidade administrativa comunicativa.

Pôr em prática a proposição de uma racionalidade administrativa democrática é tarefa árdua, como qualquer proposição de enfrentamento da racionalidade instrumentalburocrática, mas não totalmente impossível, pois se assim fosse não faria o menor sentido lutar pelo diferente ou pensar em alternativas para a educação pública deste país. Além do mais, é fundamental reconhecer que a escola precisa reinventar-se por dentro, para que seus recursos organizacionais possam contribuir efetivamente para o desenvolvimento de sua democracia interna.

\section{Notas}

1. De acordo com Habermas (1997), pretensōes de validez significam qualquer assertiva acerca do mundo social, do mundo objetivo e do mundo subjetivo, podendo ser questionadas e problematizadas no contexto da fala.

2. São muitos os autores que discutem a administração escolar dentro de uma perspectiva crítica: Paro (1993), Teixeira (1990), Pinto (1996), Fortuna (2000), Hora (1994).

3. Esse mesmo autor, posteriormente a esse trabalho, discute um conceito amplo de política que o credencia não mais apenas como luta política, mas como prática democrática que possibilita a convivência entre grupos e pessoas (PARO, 2002).

4. Habermas (1997) admite que o agir estratégico é uma forma de relação entre os indivíduos na qual um quer sempre se sobrepor ao outro, inclusive adotando como parâmetro de orientação o próprio êxito. Aqui, o que está em evidência não é a instauração de um entendimento recíproco, mas a influenciação e o mando de um sujeito sobre o outro. 


\section{Referências}

BOUflEUER, José Pedro. Pedagogia da ação comunicativa: uma leitura de Habermas. Ijuí: Unijuí, 1997.

FÉLIX, Maria de Fátima Costa. Administração escolar: um problema empresarial ou educativo? 2. ed. São Paulo: Cortez, 1985.

FORTUNA, Maria Lúcia de Abrantes. Gestão escolar e subjetividade. São Paulo: Xamã, 2000.

GENTILINI, João Augusto. Comunicação, cultura e gestão educacional. Cadernos Cedes, Campinas, v. 21, n. 54, p. 41-53, ago. 2001.

HABERMAS, Jürgen. Teoria de la acción comunicativa: complementos e estudios previos. Madrid: Catedra, 1997.

HORA, Dinair Leal da. Gestão democrática na escola. Campinas: Papirus, 1994.

LIMA, Antônio Bosco de. "Gestão democrática" ou democratização da gestão: uma análise sobre elementos instrumentalizadores da democratização da escola. In: ENCONTRO NACIONAL DE DIDÁTICA E PRÁTICA DE ENSINO, 11, 2002, Goiânia. CD-ROM.

LIMA, Licínio Carlos. A escola como organização educativa: uma abordagem sociológica. São Paulo: Cortez, 2001.

MEDEIROS, Arilene Maria Soares de. Administração educacional: definição de uma racionalidade administrativa democrática e emancipatória. 2003. Tese (Doutorado em Educação) - Programa de Pós-Graduação em Educação, Universidade Federal de São Carlos, São Carlos.

PARO, Vitor Henrique. Administração escolar: uma introdução crítica. São Paulo: Cortez, 1993. . Implicações do caráter político da educação para a administração da escola pública fundamental. Disponível em: http://www.anped.org.br. Acesso em: 09 out. 2002.

PINTO, José Marcelino Resende. Administração e liberdade: um estudo do conselho de escola à luz da teoria da ação comunicativa de Jürgen Habermas. Rio de Janeiro: Tempo Brasileiro, 1996.

SAES, Décio Azevedo Marques de; ALVES, Maria Leila. Uma contribuição teórica à análise de conflitos funcionais em instituições escolares da sociedade capitalista. Revista Brasileira de Política e Administração da Educação, Piracicaba, v. 19, n. 1, p. 11-24, jan./jun. 2003.

SIMON, Herbert A. Comportamento administrativo: estudo dos processos decisórios nas organizações administrativas. 2. ed. Rio de Janeiro: Fundação Getúlio Vargas, 1971.

TEIXEIRA, Maria Cecília Sanchez. Antropologia, cotidiano e educação. Rio de Janeiro: Imago, 1990.

WEBER, Max. Economia e sociedade. Trad., rev. e org.: Johannes Winckelmann. 5. ed. Brasília: Edunb, 2000. 


\section{Administrative rationality in education in the light of the communicative action theory}

\section{Abstract}

The aim of this article consists in presenting, in the light of communicative action theory, a critical proposition of administrative rationality for education, that can consolidate in democratic and emancipatory parameters, as a form of internal organizational restructuring of the school. This proposition faces difficulties that deserve to be properly analyzed in order not to assume a simply utopian dimension, without the smallest practical repercussion in the daily life of the school. The political-institutional difficulties reflect the relation that establishes itself between the State and the school administration. The organizational difficulties have to do with the functioning of the school by means of a School By-law, a School Council and a Pedagogical-Political Project. With this analysis, it is intended to demonstrate that the school administration reflects a tension between the policies and the practices, between the external and the internal, making possible alterations and innovations in the school.

Keywords: Administrative rationality. School by-law. School council. Pedagogical-political project. School administration. Communicative action theory.

\section{La rationalité administrative dans léducation à la lumière de la théorie de Paction communicative} Résumé

L'objectif de cet article consiste à présenter, à la lumière de la théorie de l'action comunicationnelle, une proposition critique de la rationalité administrative pour l'éducation qui puisse se consolider en paramêtres démocratiques et émancipatoires, comme forme de réstructuration organisationnelle interne de l'école. Cette proposition fait face à des difficultés qui méritent être sérieusement analysées, de manière $\grave{a}$ ne pas assumer une dimension purement utopique, sans la moindre répercussion pratique sur le quotidien de l'école. Les difficultés politico-institutionnelles reflètent la relation qui sétablit entre l'État et l'administration scolaire. Les difficultés organisationnelles se réfêrent au fonctionnement de l'école par l'intermédiaire du Régiment Scolaire, du Conseil Scolaire et du Projet Politico-Pédagogique. Par cette analyse, l'on prétend démontrer que l'administration scolaire reflète une tension entre les politiques et les pratiques, entre l'externe et l'interne, possibilitant les altérations et les innovations dans l'école.

Mots clefs : Rationalité administrative. Régiment scolaire. Conseil Scolaire. Projet politico-pédagogique. Administration scolaire. Théorie de l'action comunicationnelle.

\section{Racionalidad administrativa en la educación a la luz de la teoría de la acción comunicativa Resumen}

El objetivo de este articulo consiste en presentar, a la luz de la teoría de la acción comunicativa, una proposición critica de racionalidad administrativa para la educación que pueda consolidarse en parámetros democráticos y emancipatorios, como forma de reestructuración organizacional interna de la escuela. Esta proposición enfrenta dificultades que merecen ser debidamente analisadas, para que no asuman una dimensión simplemente utópica, sin ninguna repercusión práctica en el cotidiano de la escuela. Las dificultades político-institucionales reflejan la relación que se establece entre el estado y la administración escolar. Las dificultades organizacionales están relacionadas al funcionamiento de la escuela por meio del regimiento escolar, consejo escolar y proyecto político-pedagógico. Con este análisis, se intenta demonstrar que la administración escolar refleja una tensión entre las políticas y las prácticas, entre lo externo y lo interno, posibilitando alteraciones e innovaciones en la escuela.

Palabras-clave: Racionalidad administrativa. Regimiento escolar. Consejo escolar. Proyecto politico pedagógico. Administración escolar. Teoría de la acción comunicativa.

Recebido: 25.05 .2005

Aceito: 01.08 .2005 